\title{
Time course of change in oxygen saturation and peak expiratory flow in children admitted to hospital with acute asthma
}

\author{
W Mihatsch, G C Geelhoed, L I Landau, P N LeSouëf
}

\begin{abstract}
The time course for recovery of the arterial oxygen saturation $\left(\mathrm{SaO}_{2}\right)$ in acute childhood asthma is unknown. Serial measurements of $\mathrm{SaO}_{2}$ were made in 47 children during an acute attack of asthma that required admission to hospital. Adequate serial peak expiratory flow (PEF) measurements were possible in 28 children (mean age 8.3 years; group $A$ ), but not in the other 19 children (mean age 3.2 years; group B). Measurements of PEF and $\mathrm{SaO}_{2}$ were recorded twice daily before and 30 minutes after they had received salbutamol by nebuliser. Initial $\mathrm{SaO}_{2}$ values (mean (SD) \%) were similar in groups A and B at $92.2(3.5)$ and 92.4 (2.9). For the children in group A, PEF plateaued 36 hours after admission and $\mathrm{SaO}_{2}$ plateaued 12 hours later. Mean PEF improved after each dose of nebulised salbutamol during the first 36 hours, whereas mean $\mathrm{SaO}_{2}$ increased only after the first dose. $\mathrm{SaO}_{2}$ increased more rapidly in group $B$. Length of hospital stay was not related to initial $\mathrm{SaO}_{2}$ or PEF values. These data suggest that in children admitted to hospital for acute asthma arterial oxygen saturation is low at admission, recovers more slowly than airway function, reflects bronchodilatation with salbutamol only when $\mathrm{SaO}_{2}$ is low, and recovers more rapidly in younger children than in older children.
\end{abstract}

Measurements of forced expiration, such as peak expiratory flow (PEF) and forced expiratory volume in one second $\left(\mathrm{FEV}_{1}\right)$, have been recommended as the most useful objective measures of functional abnormality in acute asthma. ${ }^{1}$ We have shown recently that arterial oxygen saturation $\left(\mathrm{SaO}_{2}\right)$ recorded at the time of presentation to an emergency department is also useful in assessing severity and predicting outcome in acute asthma in children. ${ }^{2}$ The rate of recovery of $\mathrm{SaO}_{2}$ in children admitted to hospital for acute asthma, however, is unknown. Previous work in adults with severe acute asthma suggested that arterial oxygen saturation recovers more slowly than airway function.

The present study was undertaken in children admitted to hospital with acute asthma and was designed (1) to compare the changes over time between $\mathrm{SaO}_{2}$ and PEF in children able to perform the PEF manoeuvre; (2) to detect any effect of age on rate of recovery of $\mathrm{SaO}_{2}$; and (3) to determine whether the length of hospital stay is related to initial PEF or $\mathrm{SaO}_{2}$ or to recovery of PEF or $\mathrm{SaO}_{2}$.

\section{Methods}

SUBJECTS AND DESIGN

We studied 47 children ( 31 boys and 16 girls) admitted from the emergency department of Princess Margaret Hospital for Children with acute asthma. Children were selected according to the availability of the research worker who undertook all the measurements (WM) and classified according to the ability of the child to perform an adequate PEF manoeuvre. The PEF manoeuvre was assessed when the child presented to the department and was regarded as adequate if the child was older than 4.5 years, was able to understand the instruction, and was willing and able to cooperate. Twenty eight children (mean age 8.3 (range $4 \cdot 7-14 \cdot 3$ ) years) were able to perform an adequate manoeuvre (group A) and 19 children (mean age 3.2 (range 1.3-5.7) years) could not (group B). None of the children was considered to need supplemental oxygen by the medical staff.

$\mathrm{SaO}_{2}$ and PEF were measured when the child arrived in the emergency department and 30 minutes after administration of nebulised salbutamol $(0.02-0.04 \mathrm{ml} / \mathrm{kg}$ of a $0.5 \%$ solution of salbutamol up to a maximum of $1 \mathrm{ml}$ and made up to $2 \mathrm{ml}$ by adding normal saline) via an air or oxygen driven nebuliser. Each child was subsequently given further doses of nebulised salbutamol every one to six hours, depending on clinical assessment. Corticosteroids and methylxanthines were administered when thought necessary by the regular clinical staff. The children were reassessed each day in the morning and afternoon before and 30 minutes after having nebulised salbutamol until discharge. Discharge was decided by the clinician caring for the patient without reference to the study measurements.

\section{OXIMETRY AND PEAK EXPIRATORY FLOW}

$\mathrm{SaO}_{2}$ was measured photometrically by means of an oximeter (Radiometer, Copenhagen, Denmark) with a finger probe. A measurement was recorded when the signal was stable, there was no movement artefact, and the oximeter measured an accurate pulse rate. PEF was measured with a mini Wright peak flow meter (Clement Clarke International, London). The best of four forced expiratory flows was re- 
Table 1 Clinical details of the patients with arterial oxygen saturation $\left(\mathrm{SaO}_{2}\right)$ and peak expiratory flow $(P E F)$ (mean $(S D)$ values unless otherwise specified)

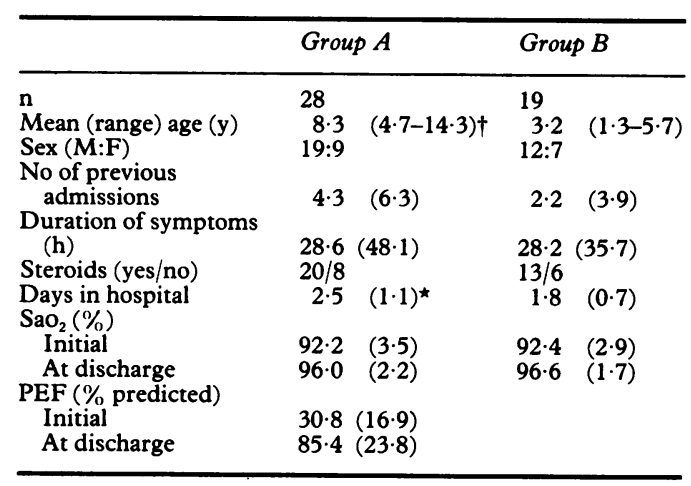

${ }^{\star} \mathrm{p}<0.02 .+\mathrm{p}<0.001$

corded. All recordings of $\mathrm{SaO}_{2}$ and PEF were made by one investigator (WM). Informed consent was obtained from a parent of each child.

\section{ANALYSIS}

PEF was expressed as a percentage of the predicted mean PEF on the basis of height. ${ }^{4}$ $\mathrm{SaO}_{2}$ and PEF measurements were expressed as mean values (with standard deviations in parentheses) for each 12 hour period from the time of admission. All other values are recorded as means with standard deviations unless otherwise noted. Analysis was carried out by means of paired and unpaired Student's $t$ tests.

\section{Results}

DETAILS OF PATIENTS

The older children (group A) stayed in hospital longer $(2.5(1 \cdot 1)$ days $)$ than the younger children (group B: $1.8(0.7)$ days; $p<0.02$ )-see table 1. There was no difference between the two groups with respect to the number of previous admissions, duration of symptoms before admission or initial $\mathrm{SaO}_{2}$ in the emergency room or at discharge. There was no difference between the boys and girls with respect to these indices in the two groups.

TIME COURSE OF $\mathrm{SaO}_{2}$ AND PEF

Mean prenebulisation levels of both $\mathrm{SaO}_{2}$ (fig $1 a$ ) and PEF (fig 1b) increased progressively during the first 36 hours after admission in group A children. PEF maintained a plateau after 36 hours whereas $\mathrm{SaO}_{2}$ was still increasing and only started to plateau 12 hours later. Initial $\mathrm{SaO}_{2}(\%)$ was similar in group A $(92 \cdot 2$ (3.5)) and group B (92.4 (2.9)). Children in group B recovered more quickly in the first 24 hours than the children in group A. By 24 hours after admission the mean $\mathrm{SaO}_{2}(\%)$ was higher for group B (96 (1.5)) than group A (94.8 (1.8); $\mathrm{p}<0.05)$. Mean $\mathrm{SaO}_{2}$ had risen above $96 \%$ by 24 hours in group $B$ and by 48 hours in group $A$ (fig 1).

RELATION BETWEEN DURATION OF ADMISSION AND PEF AND $\mathrm{SaO}_{2}$ (INITIAL LEVELS AND TIME COURSE)

Children in group A were divided into four

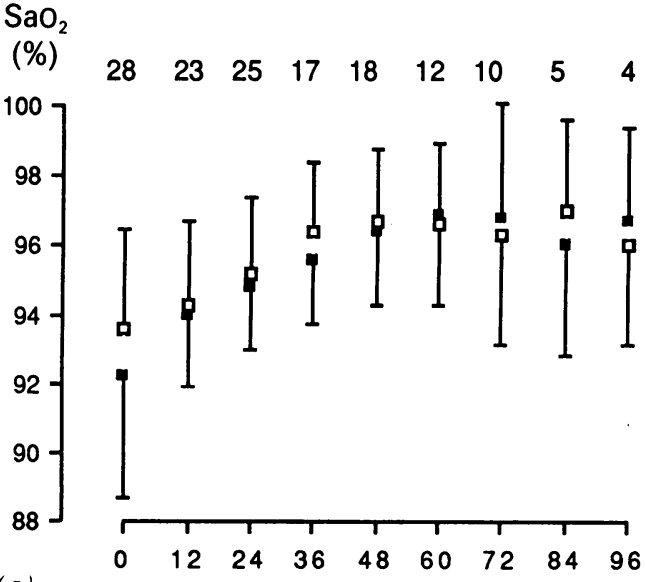

PEF

(\%)

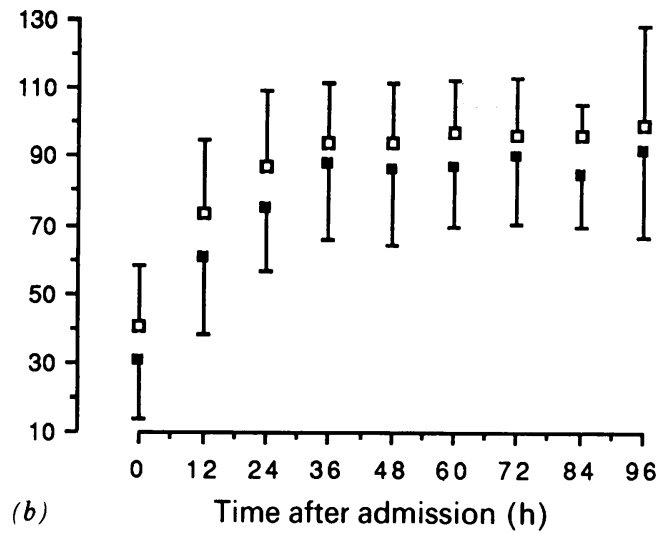

$\mathrm{SaO}_{2}$

(\%)

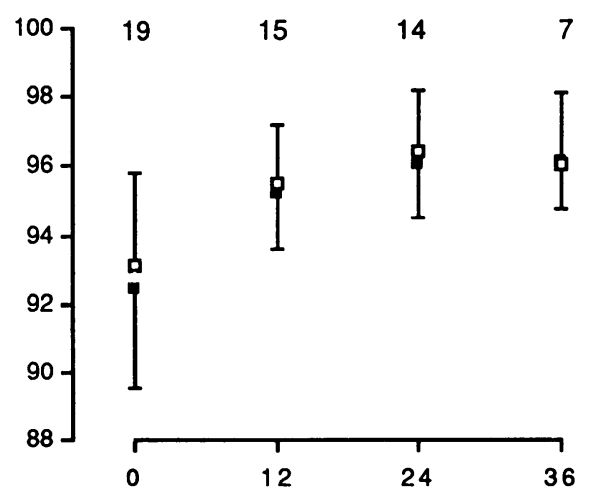

(c)

Time after admission $(h)$

Figure 1 Arterial oxygen saturation ( $\left.\mathrm{SaO}_{2}\right)$ and peak expiratory flow (PEF) before ( $)$ and after ( $\square$ ) nebulised salbutamol during the stay in hospital in group $A(a, b)$ and $B(c)$. Results are shown as means and $S D s$ at 12 hour intervals after admission. The number of children is shown above each mean.

groups according to the number of days (1-4) they stayed in hospital. There was no difference between the groups for initial $\mathrm{SaO}_{2}$ and PEF measurements in the emergency department or 12-24 hours after admission (table 2, fig 3). $\mathrm{SaO}_{2}$ at discharge was lower $(\mathrm{p}<0.05)$ in children discharged after only one day in hospital than in the children who stayed two to four days (table 2). PEF at discharge showed a 
Figure 2 Mean arterial oxygen saturation $\left(\mathrm{SaO}_{2}\right)$ and peak expiratory flow (PEF) every 12 hours after admission. Each point represents the mean prebronchodilator value. The numbers adjacent to the symbols represent the hours since admission.

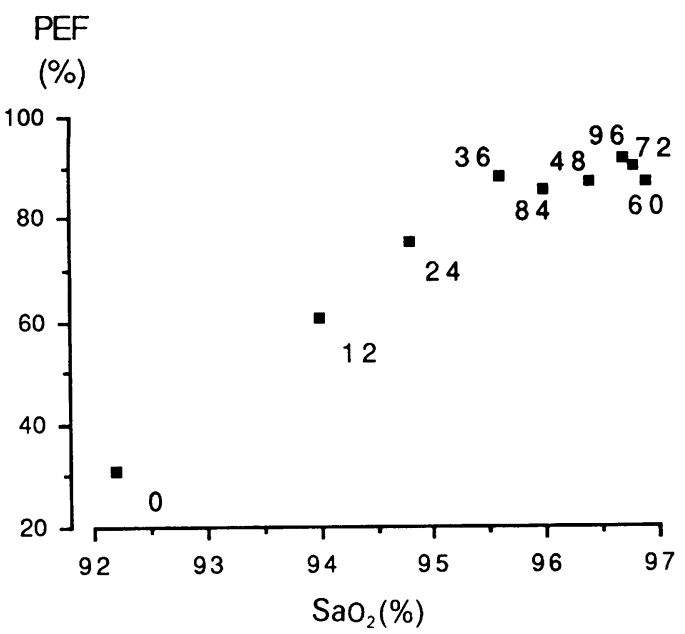

Table 2 Arterial oxygen saturation $\left(\mathrm{SaO}_{2}, \%\right.$ ) and peak expiratory flow ( $\mathrm{PEF}, \%$ predicted for height) in subgroups of patients staying different times in hospital (mean (SD) values)

\begin{tabular}{|c|c|c|c|c|}
\hline Days in hospital: & 1 & 2 & 3 & 4 \\
\hline \multicolumn{5}{|l|}{ GROUP A } \\
\hline $\begin{array}{l}\text { n } \\
\text { Sao }\end{array}$ & 5 & 11 & 5 & 7 \\
\hline Initial & $91 \cdot 2 \quad(2 \cdot 6)$ & $91.9 \quad(3.6)$ & $93.6 \quad(1 \cdot 7)$ & $92.3 \quad(5.0)$ \\
\hline $\begin{array}{l}24 \mathrm{~h} \\
\text { Discharge }\end{array}$ & $94 \cdot 2 \quad(2.5)$ & $\begin{array}{ll}95.5 & (1.5) \\
96.1 & (1.4)\end{array}$ & $\begin{array}{ll}94.6 & (1.5) \\
96.6 & (1.8)\end{array}$ & $\begin{array}{ll}94.9 & (1.9) \\
96.7 & (3.0)\end{array}$ \\
\hline \multicolumn{5}{|l|}{ PEF } \\
\hline $\begin{array}{l}\text { Initial } \\
24 \mathrm{~h}\end{array}$ & $31 \cdot 0(23 \cdot 2)$ & $\begin{array}{ll}26.2 & (14.2) \\
73.5 & (19.8)\end{array}$ & $\begin{array}{lr}23.9 & (8.0) \\
75.7 & (11.1)\end{array}$ & $\begin{array}{ll}42 \cdot 8 & (17 \cdot 4) \\
78.3 & (18 \cdot 3)\end{array}$ \\
\hline Discharge & $72.5(23.9)$ & $85.9(28.3)$ & $85.4(16.0)$ & $93.8(21 \cdot 1)$ \\
\hline \multicolumn{5}{|l|}{ GROUP B } \\
\hline $\mathrm{n}$ & 7 & 9 & 3 & \\
\hline \multicolumn{5}{|l|}{$\mathrm{SaO}_{2}$} \\
\hline $\begin{array}{l}\text { Initial } \\
24 \mathrm{~h}\end{array}$ & $92.6 \quad(4 \cdot 0)$ & $\begin{array}{ll}92 \cdot 4 & (2 \cdot 4) \\
96 \cdot 2 & (2 \cdot 0)\end{array}$ & $\begin{array}{ll}91.7 & (2.5) \\
95.3 & (1.2)\end{array}$ & \\
\hline Discharge & $95.7 \quad(1.0)$ & $96.9 \quad(2.0)$ & $97 \cdot 7 \quad(2 \cdot 1)$ & \\
\hline
\end{tabular}

Figure 3 Time course of change in arterial oxygen saturation $\left(\mathrm{SaO}_{2}\right)$ and peak expiratory flow (PEF) for patients from group $A$ according to the number of days the child stayed in hospital. Results are mean values every 24 hours after admission.

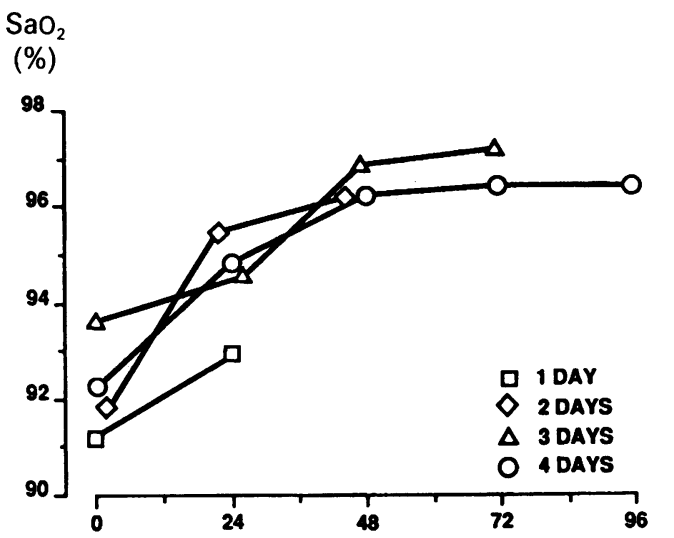

PEF

(\%pred)

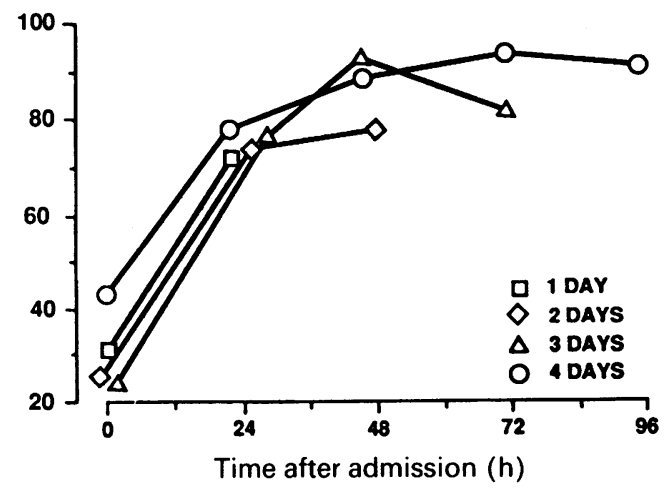

tendency to be lower in children discharged after one day in hospital than in the other children (table 2), but the difference was not significant. $\mathrm{SaO}_{2} 24$ hours after admission was related to duration of stay for the children in group A: those with an $\mathrm{SaO}_{2}$ of $94 \%$ or less 24 hours after admission stayed in hospital longer (3.1 (1.1) days) than children with an $\mathrm{SaO}_{2}$ above $94 \%$ at this time $(2.3(1.0)$ days; $\mathrm{p}<0.05)$.

\section{RESPONSE TO BRONCHODILATORS}

During recovery PEF improved after each dose of salbutamol (fig $1 b$ ) in group A children, whereas $\mathrm{SaO}_{2}$ increased only after the first dose of salbutamol, from $92.3 \%(3.5 \%)$ to $93.6 \%$ $(2.9 \%)(\mathrm{p}<0.01)$-see figure $1 a$.

\section{Discussion}

Reversible airway obstruction and regional ventilation-perfusion $(\dot{V} / \dot{Q})$ abnormalities are characteristic physiological features of acute asthma; airway obstruction is reflected by parameters such as PEF and $\mathrm{FEV}_{1}$ and $\dot{\mathrm{V}} / \dot{Q}$ mismatching by arterial hypoxaemia. ${ }^{5} \mathrm{PEF}$ and $\mathrm{SaO}_{2}$ therefore reflect important physiological components of asthma and both are now recognised as providing important objective measurements for the bedside assessment of acute asthma in children. ${ }^{12}$ In this study we have produced the first data on the time course of changes in arterial oxygen saturation and airway function in children admitted to hospital with acute asthma.

We found that $\mathrm{SaO}_{2}$ reached near optimal values 48 hours after admission, when levels reached a plateau. PEF reached a plateau 12 hours earlier, when mean values were above $85 \%$ of the predicted values. The time course of the changes in PEF that we observed was similar to that of previous studies of PEF during acute asthma in children. ${ }^{67}$ Our data show that $\mathrm{SaO}_{2}$ takes longer to recover than PEF, with a time lag of about 12 hours. This suggests that $\dot{V} / Q$ abnormalities recover more slowly than airway function, when measured as PEF, in children with acute asthma severe enough to warrant hospital admission. In this respect children may be similar to adults, as Roca et $a l^{3}$ noted that reversal of $\dot{V} / \dot{Q}$ abnormalities after an acute attack of asthma in adults was slower than recovery of airway function. The reason why $\mathrm{SaO}_{2}$ recovers more slowly than airway function is not clear, but $\mathrm{SaO}_{2}$ may be better than PEF in reflecting the effects of uneven distribution of airway narrowing caused by airway inflamation. This process perhaps resolves more slowly than the more generalised bronchodilator responsive component of airway narrowing. PEF may not be the most sensitive measure of pulmonary function for detecting minor abnormalities in the calibre of small airways. Flows at low lung volumes and the slope of phase 3 of the nitrogen washout curve are likely to be better in this regard and may be able to show that slow recovery of $\mathrm{SaO}_{2}$ is related to slow recovery of small airway function. 
$\mathrm{SaO}_{2}$ recovered more quickly in the younger children in group $B$ than in children in group $A$ (figures $1 a$ and $1 c$ ). Despite presenting with similar $\mathrm{SaO}_{2}$ in the emergency department, the younger children stayed a shorter time in hospital, had higher $\mathrm{SaO}_{2}$ values 12 and 24 hours after admission, and reached a mean $\mathrm{SaO}_{2}$ of $\geqslant 96 \%$ earlier than the older children. These data suggest that recovery from asthma is age dependent, though the two groups may not be entirely comparable in other respects as the selection criteria were based on subjective factors that may vary with age.

The time taken for recovery of PEF and $\mathrm{SaO}_{2}$ was independent of time in hospital. There was no difference in $\mathrm{SaO}_{2}$ (or in PEF in group A) initially or 24 hours after admission according to length of stay in hospital. Children discharged after only one day in hospital had lower $\mathrm{SaO}_{2}$ values on discharge in group $\mathrm{A}$ than children discharged after two to four days and a trend towards low PEF values. These data raise the possibility that length of time in hospital may reflect the practice of individual physicians rather than the severity of the attack. Rate of recovery does appear to exert a small influence on duration of admission, as children in group A with a low $\mathrm{SaO}_{2}(\leqslant 94 \%) 24$ hours after admission to hospital stayed in hospital longer than children with an $\mathrm{SaO}_{2}$ above $94 \%$ at 24 hours. The younger children of group $B$ recovered more quickly than the children in group A and the shorter time in hospital would seem to be appropriate.

Tal et $a l^{8}$ have shown that a fall in $\mathrm{SaO}_{2}$ occurs in the first 15 minutes after children receive nebulised salbutamol and it was suggested that this effect, which lasted less than half an hour, was a result of pulmonary vasodilatation or increased cardiac output. Others have found more variable changes in arterial oxygen tension after salbutamol treatment. ${ }^{910}$ So that this potential transient effect of salbutamol would not confound the results we measured $\mathrm{SaO}_{2}$ and PEF before and 30 minutes after inhalation of salbutamol, when the bronchodilator effect would still be present. ${ }^{11}$

PEF increased after each dose of nebulised salbutamol during recovery, whereas $\mathrm{SaO}_{2}$ increased significantly only after the first dose in the emergency department. These data suggest that PEF reflects changes in airway calibre better than $\mathrm{SaO}_{2}$, especially when hypoxaemia is only mild. McFadden $e t a l^{5}$ found that patients having mild to moderate airways obstruction when they presented to an emergency department had hypoxaemia and respiratory alkalosis. As hypoxaemia was present despite alveolar hyperventilation $\dot{V} / \dot{Q}$ mismatching was implicated. Severe airway obstruction was characterised by scvere hypoxaemia and hypercapnia. Salbatamol caused significant immediate improvement in $\mathrm{SaO}_{2}$ in our study only when substantial airway obstruction (mean PEF $<40 \%$ ) was present.

$\mathrm{SaO}_{2}$ measurements made during our study were not available to the patients' physicians, so we cannot comment on their value in practice. As PEF reflects only one of the relevant physiological aspects of asthma, however, a combination of a measure of airway function and $\mathrm{SaO}_{2}$ would allow a more comprehensive physiological assessment and might lead to improvements in management. Oximetry may also prove helpful in monitoring the severity of an attack of asthma in children too young to cooperate in the measurement of PEF.

1 Anonymous. Acute asthma. [editorial]. Lancet 1986;ii: 131-3.

2 Geelhoed GC, Landau LI, LeSouëf PN. Predictive value of oxygen saturation in emergency evaluation of asthmatic children. Br Med J 1988;297:395-6.

3 Roca J, Ramis LI, Rodriguez-Roisin R, Ballester E, Monteserat JM, Wagner PD. Serial relationships between ventilation-perfusion inequality and spirometry in acute severe asthma requiring hospitalisation. Am Rev Respir Dis 1988;137:1055-61.

4 Godfrey S, Kamburoff PL, Nairn JR. Spirometry, lung volumes and airway resistance in normal children aged 5 to 18 years. Br J Dis Chest 1970;64:15-24.

5 McFadden ER Jr, Lyons HA. Arterial blood gas tension in Asthma. N Engl J Med 1986;278:1027-32.

6 Storr J, Barrel E, Barry W, Lenney W. Effect of a single oral dose of prednisolone in acute childhood asthma. Lancet 1987;316:879-82.

7 Meyer K, Gurwitz D, Levison H. Corticosteroids in status asthmaticus. J Pediatr 1980;96:596-9.

8 Tal A, Pasterkamp H, Lehay F, Arterial oxygen desaturation following salbutamol inhalation in acute asthma. Chest 1986;6:868-9.

9 Murray AB, Hardwick DF, Pirie GE, Fraser BM. The effects of pressurized isoproterenol and salbutamol in asthmatic children. Pediatrics 1974;54:746-56.

10 Palmer KNV, Legg AS, Hamilton WED, Diament ML. Comparison of effects of salbutamol and isoprenaline on spirometry and blood gas tension in bronchial asthma. $B$ Med J 1970;ii:23-4.

11 Becker AB, Nelson NA, Simons FER. Inhaled salbutamol (albuterol) vs epinephrine in the treatment of acute asthma in children. J Pediatr 1983;102:465-9. 